\title{
Portfólio como estratégia de ensino, aprendizagem e avaliação: percepção de discentes e docentes de Odontologia
}

Lydia de Brito Santos*; Ana Carla Ferreira Carneiro Rios**; Hianka Renata***; Karina Maia Cunha $^{* * *}$; Priscila Alves Torreão***

* Doutora em Prótese Dentária, Professora Titular, Curso de Odontologia, Universidade Estadual de Feira de Santana

** Mestre em Clínica Odontológica, Professora Assistente, Curso de Odontologia, Universidade Estadual de Feira de Santana

*** Estudante, curso de Odontologia, Universidade Estadual de Feira de Santana

Recebido: 16/03/2020. Aprovado: 30/11/2020.

\section{RESUMO}

O objetivo do presente estudo foi analisar a percepção de estudantes e professores de odontologia, a respeito do processo de construção e apresentação do portfólio reflexivo enquanto estratégia de ensino, aprendizagem e avaliação, na disciplina Clínica Integrada do Curso de Odontologia da Universidade Estadual de Feira de Santana (UEFS). Trata-se de um estudo transversal de natureza qualitativa descritiva, cuja coleta de dados se deu durante o período letivo do semestre 2014/1. A população do estudo foram os professores da referida disciplina, bem como os estudantes matriculados no semestre em que a pesquisa foi desenvolvida. A coleta de dados foi realizada por meio de entrevista semiestruturada, contendo nove questões para estudantes e sete para professores. Os dados foram avaliados a partir do método de Análise de Conteúdo. Para apresentação dos resultados foram elaboradas três hipóteses: 1. O uso do portfólio constitui uma estratégia que favorece maior compreensão por estudantes e professores a respeito do que foi ensinado e, consequentemente, índices mais elevados de aprendizagem significativa; 2. O portfólio se constitui um instrumento facilitador no processo de reelaboração do conhecimento por estudantes e professores, oferecendo oportunidade de reflexão sobre o progresso dos estudantes, além de contribuir para a autoavaliação tanto do corpo docente quanto discente; 3. A aplicação do portfólio favorece uma gestão participativa na estratégia de avaliação formativa, em que o docente, enquanto sujeito facilitador do processo de construção do conhecimento reflexivo, possibilita ao estudante desenvolver as competências de autonomia, independência, criatividade e autocrítica. Dessa forma a construção do portfólio por estagiários em Clínica Integrada Odontológica se constitui um potente indutor e potencializador do trabalho em equipe, se estabelecendo como estratégia educacional que permite (re)significar e aprofundar o conhecimento, ao tempo que propicia a consolidação do aprendizado. A construção do portfólio clínico exige do estudante um nível de reflexão crítica que favorece o crescimento do estudante, enquanto cidadão e futuro profissional; estimulando a participação ativa nos acontecimentos do mundo real, principalmente aqueles ligados à saúde. O portfólio acadêmico pode ser admitido como estratégia de ensino, aprendizagem e avaliação formativa, crítica, reflexiva, criativa e dialética, que estimula e valoriza a participação do aluno. Ademais, a utilização do portfólio no estágio em Odontologia é uma maneira de ampliar, (re)pensar e inovar o ensino de graduação na perspectiva de um instrumento/estratégia de estimulação do pensamento acadêmico.

Descritores: Portfólio. Ensino. Avaliação Educacional. 


\section{INTRODUÇÃO}

A utilização do portfólio, tem conquistado destaque entre os recursos metodológicos aplicados no processo de ensino-aprendizagem, bem como na avaliação discente, firmando-se como instrumento-estratégia de estimulação do pensamento reflexivo. O portfólio permite ao educando documentar, registrar e estruturar o processo de sua própria aprendizagem, visto que a construção se pauta na pactuação prévia entre educador e educando, possibilitando o trabalho colaborativo na articulação e na solução de problemas complexos ${ }^{1}$.

Originalmente, o termo portfólio, do italiano portafoglio, que significa "recipiente onde se guardam folhas soltas", começou a ser empregado em artes plásticas, em que o artista fazia uma seleção de trabalhos que exprimiam sua produção. No ambiente educacional a idéia permanece a mesma. $\mathrm{O}$ portfólio permite que o trabalho desenvolvido pelo estudante seja observado de maneira processual, buscando levar a avaliação além dos patamares das provas e testes $^{2}$.

A composição do portfólio caracteriza-se pela coletânea das produções do estudante, as quais representam evidências de sua aprendizagem. É organizado pelo próprio aluno, dentro dos parâmetros pactuados no início do período letivo. Desta forma o estudante tem autonomia com relação ao formato de apresentação do seu portfólio, desde que não se contraponha aos objetivos educacionais firmados previamente.

O portfólio é um procedimento de avaliação que permite aos alunos participarem da formulação dos objetivos de sua aprendizagem ${ }^{3}$. Quando é utilizado como mídia mediadora do planejamento, desenvolvimento e resultados nas atividades ambulatoriais desenvolvidas por estudantes de Odontologia, o portfólio propicia momentos de diálogo entre os indivíduos envolvidos no processo de construção do conhecimento, de forma que educador e educando, em conjunto, possam acompanhar e avaliar o progresso do aluno, com conseqüente apropriação do conhecimento.

Diante da relevância do tema, o presente estudo, realizado no âmbito do curso de Odontologia da Universidade Estadual de Feira de Santana (UEFS), Bahia, particularizou o uso do portfólio na Disciplina Clínica Integrada, como instrumento de investigação, visto que o corpo docente da referida disciplina encontrou no portfólio, enquanto instrumento mediador da avaliação da aprendizagem, subsídios favoráveis para a construção do conhecimento.

Ao verificar os portfólios dos estudantes das primeiras turmas em que este recurso foi estabelecido como elemento da avaliação clínica, as pesquisadoras, então docentes do referido componente curricular, perceberam que os portfólios se constituíam em coletâneas dos procedimentos clínicos realizados pelos alunos ao longo da assistência aos pacientes, não apresentando, na grande parte, nenhuma reflexão sobre a aprendizagem considerada significativa. Contudo, ao longo do tempo mudanças foram acontecendo.

Apesar de reconhecer a importância da autonomia discente na elaboração de seu portfólio, a Clínica Integrada do Curso de Odontologia da UEFS exige alguns tópicos obrigatórios na sua construção: o plano de tratamento aprovado por cada paciente assistido pelo aluno, o cronograma de atendimento e a descrição dos procedimentos planejados para cada atendimento. Assim, para delinear o que compõe o portfólio em estudo, é preciso contextualizar a metodologia de "ensinagem" utilizada no componente curricular supracitado.

A elaboração do portfólio inicia-se após a consulta de acolhimento do paciente em que o estudante realiza pelo menos entrevista, exame 
físico, preenchimento do prontuário e solicitação de exames complementares. $\mathrm{Na}$ sequência acontece o primeiro momento de conversa entre o estudante e os professores supervisores, para discussão inicial das necessidades clínicas observadas pelo estudante durante o exame. A partir deste momento o estudante inicia o relato do sumário da condição clínica dos pacientes sobre sua responsabilidade, das orientações fornecidas pelos professores que participaram da discussão, dúvidas e a percepção dos desafios que a assistência clínica lhe confere naquele momento. Essa descrição é livre, atrela-se ao perfil de cada estudante e serve como trilho norteador do levantamento bibliográfico a ser realizado para fundamentar o primeiro elemento obrigatório - o plano de tratamento, demonstrando a fundamentação teórica para tal construção. Assim, as pastas podem conter artigos científicos, fotografias, desenhos, gráficos, fichamentos, organogramas, ou qualquer elemento gráfico que possa representar a síntese do estudo realizado.

A partir da concordância do corpo docente com o plano de tratamento traçado e aprovação deste pelo paciente, o estudante traçará o cronograma de atendimento que, além de organizar a assistência clínica, serve para nortear a elaboração do segundo elemento obrigatório do portfólio, a descrição dos procedimentos por sessão clínica, que deverá ser apresentada ao corpo docente antes da realização de cada procedimento.

Nestes registros os estudantes podem descrever dificuldades, obstáculos ou facilidades, visto que, muito mais do que um recurso classificatório, este elemento do portfólio tem o propósito de estimular o estudo antecipado para organizar o planejamento diário de forma adequada e integral, e conseqüentemente proporcionar o desenvolvimento do pensamento crítico e reflexivo. Aqui também podem ser registradas alterações no planejamento clínico.

No portfólio consta também o barema de avaliação somativa, que é composto pelos seguintes indicadores: conhecimento (estudo prévio e apropriação teórica); atitude (aplicação do protocolo de biossegurança, zelo pelo material e equipamento, organização da mesa e do box de atendimento, apresentação de todo material necessário); e procedimento (destreza manual e ações clínicas ordenadas culminando no cumprimento do planejamento do tratamento traçado). $\mathrm{O}$ barema é preenchido ao final de cada turno de atividade, com o propósito de feedback processual.

Assim, o presente estudo teve como objetivo analisar a percepção de estudantes e professores a respeito do processo de construção e apresentação do portfólio reflexivo enquanto estratégia de ensino, aprendizagem e avaliação, na disciplina da Disciplina Clínica Integrada da UEFS.

\section{MATERIAL E MÉTODOS}

Trata-se de um estudo transversal de natureza qualitativa descritiva, cuja coleta de dados se deu durante período letivo do semestre 2014/1.

A população do estudo foi constituída pelos professores da disciplina da Disciplina Clínica Integrada da UEFS, bem como os estudantes matriculados naquele semestre.

O Projeto de pesquisa foi aprovado pelo CEP UEFS (CAAE 32743514.7.0000.0053). Participaram do estudo 11 estudantes e sete docentes, que concordaram assinaram o Termo de Consentimento Livre e Esclarecido.

A coleta de dados foi realizada por meio de entrevista semiestruturada, contendo nove questões para estudantes e sete para professores, realizadas por um pesquisador previamente treinado. As questões analisadas do roteiro utilizado constam do quadro 1. 
Quadro 1. Questões norteadores das entrevistas

\begin{tabular}{|c|c|}
\hline ESTUDANTES & DOCENTES \\
\hline $\begin{array}{l}\text { 1. Como você avalia o portfólio de atividades enquanto instrumento de } \\
\text { ensino/avaliação? } \\
\text { 2. Quais são os pontos fortes do portfólio? } \\
\text { 3. Quais são os pontos frágeis do portfólio? } \\
\text { 4. Em quais aspectos este instrumento pode ser melhorado? } \\
\text { 5. Que outro instrumento poderia ser utilizado para ensino e avaliação } \\
\text { das atividades clínicas disciplina Clínica Integrada substituindo ou } \\
\text { complementando o portfólio? } \\
\text { 6. Que habilidades você acredita ter adquirido/exercitado a partir da } \\
\text { metodologia participativa e construção de portfólios utilizada na } \\
\text { disciplina? } \\
\text { 7. Como você se sente quando é avaliado pelo professor por este } \\
\text { instrumento? } \\
\text { 8. O portfólio é uma forma coerente de avaliação? } \\
\text { 9. Defina em uma frase o sentimento/sensação experimentado por você } \\
\text { ao final da disciplina. Estes roteiros foram designados fontes primárias. }\end{array}$ & $\begin{array}{l}\text { 1. Descreva como é confeccionado o portfólio de } \\
\text { atividades no seu componente curricular. } \\
\text { 2. Como você avalia este instrumento de } \\
\text { ensino/avaliação? Quais são os pontos fortes do } \\
\text { portfólio? } \\
\text { 3. Quais são os pontos frágeis do portfólio? } \\
\text { 4. Em quais aspectos este instrumento pode ser } \\
\text { melhorado? } \\
\text { 5. Que outro instrumento poderia ser utilizado para } \\
\text { ensino e avaliação das atividades clínicas } \\
\text { substituindo ou complementando o portfólio? } \\
\text { 6. Se você pudesse escolher entre a metodologia } \\
\text { tradicional e a metodologia ativa como } \\
\text { instrumento de aprendizagem, que metodologia } \\
\text { você elegeria? Reflita sobre sua resposta. } \\
\text { 7. O portfólio é uma forma coerente de avaliação? }\end{array}$ \\
\hline
\end{tabular}

Os dados foram avaliados a partir do método de Análise de Conteúdo. A utilização desta técnica metodológica permitiu dar sentido e significado a diversidade de informações presentes nas idéias expressadas por docentes e discentes a respeito do portfólio enquanto instrumento de ensino, aprendizagem e avaliação que possibilitou a apresentação destes resultados em duas categorias temáticas: "Processo de construção do portfólio como estratégia de ensino, aprendizagem" e " Apresentação e análise do portfólio como recurso de avaliação".

A fase de pré-análise envolveu a leitura "flutuante" dos questionários aplicados a estudantes e professores numa perspectiva de formulação dos indicadores que pudessem orientar a interpretação e a organização formal dos dados coletados. Buscou-se neste momento obedecer às regras de exaustividade (exaurir as informações, numa perspectiva de não omitir nada); homogeneidade (subdividir os dados por temas, obtidos por indivíduos semelhantes, ou seja, aqueles oriundos dos discentes e aqueles outros dos docentes); pertinência (informações obtidas que sejam condizentes com o conteúdo e objetivo da pesquisa $)^{4}$.
$\mathrm{Na}$ etapa de exploração/preparação do material as informações foram agrupadas numa perspectiva de elucidar as seguintes hipóteses: 1 . O uso do portfólio constitui uma estratégia que favorece uma compreensão maior por estudantes e professores a respeito do que foi ensinado e consequentemente índices mais elevados de aprendizagem significativa; 2 . O portfólio se constitui um instrumento facilitador no processo de reelaboração do conhecimento por estudantes e professores, oferecendo oportunidade de reflexão sobre o progresso dos estudantes, além de contribuir para a auto avaliação tanto do corpo docente, quanto discente; 3. A aplicação do portfólio favorece uma gestão participativa na estratégia de avaliação formativa, em que o docente, enquanto sujeito facilitador do processo de construção do conhecimento reflexivo possibilita ao estudante desenvolver as competências de autonomia, independência, criatividade e autocrítica.

$\mathrm{Na}$ fase de tratamento dos resultados, amparadas nos resultados brutos, as pesquisadoras procuraram torná-los significativos e válidos, através de inferência e interpretação de conceitos oriundos da revisão literária prévia e da 
comunicação dos informantes, que culminou no estabelecimento das três hipóteses. Esta etapa visou evidenciar se existe ou não uma linha de raciocínio que unifique os conceitos e hipóteses, ao mesmo tempo em que busca esclarecer as semelhanças que possam haver entre as diferentes hipóteses, visto que os conceitos podem ou não se ajustar, e as hipóteses levantadas são verdadeiras ou censuráveis.

\section{RESULTADOS}

Este capítulo foi construído com o escopo de explicitar informações e reflexões dos estudantes e professores orientadores que permitiram as pesquisadoras tratarem as três hipóteses elaboradas. Vale destacar que as hipóteses foram elaboradas a partir das categorias temáticas "Processo de construção do portfólio como estratégia de ensino, aprendizagem" e "Apresentação e análise do portfólio como recurso de avaliação".

Os quadros 2 a 4 sumarizam as impressões expressas por estagiários e professores que confirmam e negam as hipóteses elaboradas.

Quadro 2. Hipótese 1 - O uso do portfólio constitui uma estratégia que favorece uma compreensão maior por estudantes e professores a respeito do que foi ensinado e conseqüentemente índices mais elevados de aprendizagem significativa

\begin{tabular}{|c|c|c|}
\hline & ESTAGIÁRIOS & PROFESSORES SUPERVISORES \\
\hline 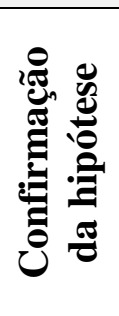 & $\begin{array}{l}\text { Estudo prévio para o planejamento do } \\
\text { tratamento. } \\
\text { Motiva o aluno a cumprir suas obrigações. } \\
\text { Promove o estudo, e dá mais segurança. } \\
\text { Permite visualizar a produção. } \\
\text { Essencial para um aprendizado mais } \\
\text { completo. }\end{array}$ & $\begin{array}{l}\text { Um instrumento que alia a avaliação do exercício de } \\
\text { construção do conhecimento teórico com } \\
\text { desenvolvimento de habilidade motora consciente. } \\
\text { No estágio, que é o elemento curricular que me } \\
\text { vinculo, eu acredito que a utilização de recursos da } \\
\text { metodologia ativa amplia a possibilidade de } \\
\text { aprendizado. }\end{array}$ \\
\hline 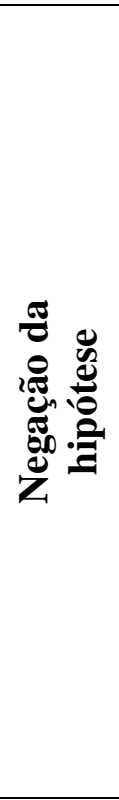 & $\begin{array}{l}\text { Necessidade de que todos os professores } \\
\text { conheçam como funciona. } \\
\text { Falta de avaliação por parte dos } \\
\text { professores dos planejamentos. } \\
\text { Professores não cobram o planejamento } \\
\text { e atribuem notas altas, assim incentiva o } \\
\text { aluno ao mau hábito de não planejar o } \\
\text { procedimento. } \\
\text { Precisa uma discussão mais completa } \\
\text { sobre o que vai ser feito. }\end{array}$ & $\begin{array}{l}\text { Não deve ser extenso, pois dificulta o cotidiano da } \\
\text { clínica. } \\
\text { Difícil à tabulação de resultados. } \\
\text { Existem falhas na aplicação desta metodologia, pois o } \\
\text { professor ainda o aplica muito mais como instrumento } \\
\text { de avaliação classificatória. Ou seja, o que tem a ser } \\
\text { modificado diz respeito ao modo como o instrumento } \\
\text { está sendo aplicado e não no instrumento em si. Se } \\
\text { chegar à aplicação precisa do instrumento, talvez aí eu } \\
\text { tenha condição de detectar pontos que podem ser } \\
\text { melhorados. } \\
\text { Requer preparação e calibração dos professores } \\
\text { envolvidos além do constante diálogo entre os sujeitos, } \\
\text { o que não vem acontecendo na prática. } \\
\text { Falta "espaço" que estimule a expressão mais direta da } \\
\text { avaliação do aluno, tipo dificuldades, pontos fortes e } \\
\text { fracos. Falta também espaço para o professor manifestar } \\
\text { seus comentários - feedback. }\end{array}$ \\
\hline
\end{tabular}


Quadro 3. Hipótese 2 - O portfólio se constitui um instrumento facilitador no processo de reelaboração do conhecimento por estudantes e professores, oferecendo oportunidade de reflexão sobre o progresso dos estudantes, além de contribuir para a auto avaliação tanto do corpo docente, quanto discente

\begin{tabular}{|c|c|c|}
\hline & ESTAGIÁRIOS & PROFESSORES SUPERVISORES \\
\hline 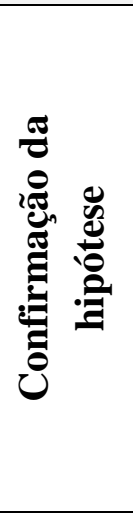 & $\begin{array}{l}\text { Muito bom. Identifica onde o aluno precisa } \\
\text { melhorar. } \\
\text { Avaliar seu desempenho e deficiência a } \\
\text { partir das notas diárias, e assim se esforçar } \\
\text { para melhorar. } \\
\text { Interação professor/aluno. } \\
\text { Planejamento prévio dos procedimentos e } \\
\text { discussão com o aluno antes da execução. } \\
\text { Possibilita experimentar situações ainda não } \\
\text { executadas. }\end{array}$ & $\begin{array}{l}\text { Instrumento dinâmico que vai sendo construído de } \\
\text { acordo com as demandas da clínica; possibilita } \\
\text { auto avaliação do aluno e avaliação da evolução } \\
\text { do discente ao longo do semestre. } \\
\text { Trata-se de um instrumento inovador, interativo, } \\
\text { reflexivo e construído ao longo do semestre pela } \\
\text { interação entre os professores e estudantes. } \\
\text { Transparências para todos os indivíduos } \\
\text { envolvidos no processo de aprendizagem. }\end{array}$ \\
\hline 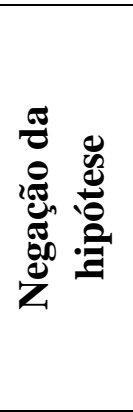 & $\begin{array}{l}\text { Rigidez. } \\
\text { Falta de coerência entre produção e } \\
\text { avaliação. } \\
\text { Sem critérios claros e muito subjetivos. } \\
\text { Não existe uma padronização entre os } \\
\text { professores. }\end{array}$ & $\begin{array}{l}\text { Precisa melhorar a sensibilização e conscientização } \\
\text { de professores e estudantes com relação ao } \\
\text { instrumento, destacando seus benefícios para } \\
\text { aprofundamento do conhecimento no processo de } \\
\text { aprendizagem, para que o instrumento seja aplicado } \\
\text { em consonância com seus princípios norteadores. } \\
\text { Necessidade de comprometimento do estudante com } \\
\text { a autonomia na construção do conhecimento. }\end{array}$ \\
\hline
\end{tabular}

\section{DISCUSSÃO}

As metodologias ativas baseiam-se em estratégias de ensino fundamentadas na concepção pedagógica crítico-reflexiva, que permitem uma leitura e intervenção sobre a realidade, favorecendo a interação entre os diversos sujeitos e valorizando a construção coletiva do conhecimento e seus diferentes saberes e cenários de aprendizagem. Além disso, são práticas que estimulam a criatividade na construção de soluções aos problemas e que promovem a liberdade no processo de pensar e de agir ${ }^{1}$.

Assim, entre os recursos inovadores do processo de ensino-aprendizagem e de avaliação, destaca-se o portfólio, como instrumento-estratégia de estimulação do pensamento reflexivo ${ }^{1}$. No quadro 2 verifica-se na impressão expressa por estagiários e professores, na coluna confirmação da hipótese, que é reconhecida a acuidade da construção do portfólio clínico enquanto instrumento de aprendizagem que propicia desenvolver habilidades de avaliar, sistematizar e decidir as condutas mais adequadas, baseadas em evidências científicas, balizando a tomada de decisões. Ao analisar as contribuições do portfólio apresentadas por estagiários, podemos perceber que esse instrumento estimula o estudo com antecedência para organizar o planejamento do tratamento de forma adequada e integral, consequentemente proporciona o desenvolvimento do pensamento crítico e reflexivo, de modo que o aluno passa a ter uma postura ativa na construção do conhecimento. Souza et al ${ }^{5}$ reconhecem que o uso de metodologias ativas propõe uma mudança na forma de construção do conhecimento acadêmico, estimula os discentes a relacionar as suas vivencias e interagir sobre os assuntos e, posteriormente, concluir uma graduação mais qualificada. 
Quadro 4. Hipótese 3 - A aplicação do portfólio favorece uma gestão participativa na estratégia de avaliação formativa, em que o docente, enquanto sujeito facilitador do processo de construção do conhecimento reflexivo possibilita ao estudante desenvolver as competências de autonomia, independência, criatividade e autocrítica

\begin{tabular}{|c|c|c|}
\hline & ESTAGIÁRIOS & PROFESSORES SUPERVISORES \\
\hline 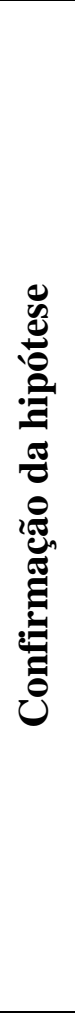 & $\begin{array}{l}\text { Com o portfólio o conhecimento é } \\
\text { construído e não apenas repassado. } \\
\text { Muito bom e muitas vezes } \\
\text { necessário. } \\
\text { Muito bom. Identifica onde o aluno } \\
\text { precisa melhorar. } \\
\text { Não causa a impressão ruim ou } \\
\text { injusta. } \\
\text { Sinto estimulado a melhorar, apesar } \\
\text { de às vezes não achar justa a } \\
\text { avaliação. } \\
\text { Autocrítica. } \\
\text { Poder de análise clínica. }\end{array}$ & $\begin{array}{l}\text { Estimula a autonomia na construção do conhecimento. } \\
\text { Criação de hábitos e rotinas favoráveis ao processo de } \\
\text { formação profissional. } \\
\text { Criar possibilidade de auto avaliação discente. } \\
\text { Estimula a autonomia na construção do conhecimento. } \\
\text { Possibilita acompanhamento docente do aprimoramento } \\
\text { teórico das técnicas que estão sendo aplicadas na assistência } \\
\text { aos pacientes. } \\
\text { Constitui-se um arquivo bem completo do processo de } \\
\text { avaliação, possibilitando que tanto professor, quanto aluno } \\
\text { tenha noção da evolução das atividades desenvolvidas e } \\
\text { norteia com precisão o computo final da nota. } \\
\text { O portfólio se constitui um instrumento inovador, } \\
\text { possibilitando uma avaliação formativa de fato, em que } \\
\text { professor e aluno podem acompanhar o desenvolvimento da } \\
\text { aprendizagem clínica. Porém, é um instrumento que requer } \\
\text { mais tempo do professor dedicado individualmente para cada } \\
\text { aluno, para discussão e aprimoramento do conteúdo arquivado } \\
\text { na construção do portfólio. Quando este tempo não é } \\
\text { disponibilizado o portfólio torna-se apenas um fichamento. }\end{array}$ \\
\hline 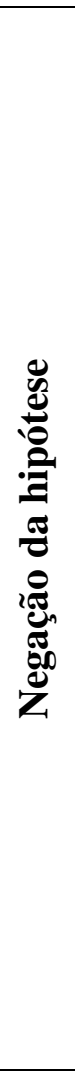 & $\begin{array}{l}\text { Alguns professores não olham e não } \\
\text { corrigem. } \\
\text { Falta de vistoria diária por um } \\
\text { professor. } \\
\text { Alguns professores não cobram o } \\
\text { planejamento e atribuem notas altas, } \\
\text { assim incentiva o aluno ao mau } \\
\text { hábito de não planejar o } \\
\text { procedimento. } \\
\text { Deveria servir como estímulo e não } \\
\text { como ferramenta de avaliação. }\end{array}$ & $\begin{array}{l}\text { É necessário que o professor saia do lugar de detentor do } \\
\text { conhecimento para possibilitar a discussão do conhecimento } \\
\text { trazido (desenvolvido) pelo estudante. } \\
\text { Requer preparação e calibração dos professores envolvidos } \\
\text { além do constante diálogo entre os sujeitos, o que não vem } \\
\text { acontecendo na prática. } \\
\text { Existem falhas na aplicação desta metodologia, pois o } \\
\text { professor ainda o aplica muito mais como instrumento de } \\
\text { avaliação classificatória. Ou seja, o que tem a ser modificado } \\
\text { diz respeito ao modo como o instrumento está sendo aplicado } \\
\text { e não no instrumento em si. Se chegar a aplicação precisa do } \\
\text { instrumento, talvez ai eu tenha condição de detectar pontos } \\
\text { que podem ser melhorados. } \\
\text { Precisa haver um treinamento, uma sensibilização, um } \\
\text { trabalho pedagógico constante de preparação dos professores. } \\
\text { Da mesma forma, é preciso explicar muito bem aos estudantes } \\
\text { o sentido e a metodologia de utilização de portfólio. } \\
\text { É necessário que todos os envolvidos tenham consciência que } \\
\text { é um instrumento dinâmico, em construção, que necessita ser } \\
\text { refletido e avaliado enquanto instrumento e quando necessário } \\
\text { adaptado, modificado. }\end{array}$ \\
\hline
\end{tabular}


Ao analisar o quadro 3 verifica-se que depoimentos de estudantes e professores reforçam a característica atribuída por Silva et al. ${ }^{6}$ ao portfólio (confirmação da hipótese 2). Ao analisar os questionários respondidos pelos estudantes verificou-se que o portfólio foi considerado como um bom instrumento, apontado até mesmo como necessário, sendo útil para o aluno identificar itens em que precisa melhorar, portanto se constituindo num instrumento de autoavaliação.

No entanto, percebe-se nos argumentos considerados negação da hipótese, que algumas características como "estímulo à autonomia para educação continuada" e "individualização do aprendizado", atribuídas ao portfólio, enquanto instrumento facilitador do processo de apropriação e aprofundamento dos conhecimentos acadêmicos precisam ser melhor esclarecidas, tanto para estudantes quanto para professores orientadores do estágio, visto que o portfólio enquanto estratégia norteadora infere uma dinâmica diferenciada ao cotidiano de estudo de cada estagiário, no entanto este recurso é utilizado como mecanismo concreto de heteroavaliação somativa de indivíduos em processo de formação profissional. Esta dualidade de função do portfólio pode ter levado alguns estagiários a considerarem o portfólio um método avaliativo rígido por alguns e por vezes injusto, por outros, ao considerarem seus critérios subjetivos e sem clareza. O portfólio ainda foi considerado por parte desses estudantes como algo desnecessário onde deveria servir como estímulo e não como uma atividade avaliativa.

De acordo com alguns estudantes entrevistados, em algumas situações, o portfólio não é vistoriado diariamente, de modo que são atribuídas notas diárias ao desempenho do estagiário sem a devida avaliação. Ainda em relação à atribuição de notas pela construção do portfólio, destacou-se a pontuação de forma subjetiva sem considerar os critérios expressos no barema de avaliação e sem padronização entre os professores. $\mathrm{Na}$ análise deste contexto, é valido destacar que a aplicação do portfólio no ensino universitário, ou qualquer outra metodologia ativa de ensino-aprendizagem não é algo solto e sem parâmetros de acompanhamento e avaliação, faz-se necessário que professores universitários se incumbam em sua formação continuada, se atualize com relação aos recursos pedagógicos que oferecem efetividade na formação profissional e educação de adultos.

Por esse motivo, estudos sinalizam a necessidade de qualificação docente para o uso das metodologias ativas, pois apesar dos obstáculos que ainda se percebe na aplicação destes métodos, estudos demonstram resultados positivos na construção da autonomia do educando quando aplicadas estas metodologias $3,7,8$. Vale destacar que ainda hoje a escassez de referenciais teóricos para planejar a ação pedagógica na formação de profissionais de saúde e o uso excessivo de técnicas de ensino tradicionais pelos professores universitários dificultam uma análise crítica do método aplicado.

Com base nas DCN para os cursos de Odontologia, as ações pedagógicas devem ocorrer de forma articulada e integrada entre os trabalhadores da área da saúde, usuários e sociedade civil e convergentes com as propostas dos serviços de saúde, deste modo faz-se necessário aprimorar métodos efetivos de aprendizagem que propicie interação ensinoserviço. No grupo pesquisado houve sugestão de estagiários que o acompanhamento da construção do portfólio seja continuado, com cobrança mais efetiva por parte dos professores no que diz ao referencial teórico, porém com uma menor rigidez com relação à forma de apresentação do mesmo. Outra sugestão mencionada foi que haja a explicação do instrumento, sendo discutido com os estagiários antes de iniciar sua execução, esclarecendo todos os itens que serão cobrados na avaliação. Dentro deste contexto, podemos 
observar que o portfólio é muito bem aceito como parte do processo avaliativo, sem a rigidez da avaliação somativa.

Por outro lado, o portfólio também incentiva o aluno a colecionar suas reflexões e impressões sobre a disciplina, opiniões, dúvidas, dificuldades, reações aos conteúdos e aos textos estudados, às técnicas de ensino, sentimentos e situações vividas nas relações interpessoais, oferecendo subsídios para a avaliação dele, a do educador, a dos conteúdos e a das metodologias de ensinoaprendizagem, assim como para estimar o impacto da própria disciplina ${ }^{9}$.

A utilização do portfólio no Estágio Supervisionado se efetivou como um instrumento capaz de documentar ações e reflexões na clínica odontológica, se constituindo como uma ferramenta que facilitou $\mathrm{o}$ processo de aprendizagem, ao tempo que também ressignificou o papel do professor orientador, e consequentemente o processo de ensinagem. Estudantes e professores perceberam que a preparação/estruturação do portfólio assegurou melhoria na qualidade da aprendizagem dos estudantes, e concomitantemente propiciou a reelaboração das ações docentes para efetivação do processo de ensinagem. Destaque-se que ao longo do período letivo, em alguns momentos ensino/aprendizagem se fundiram tanto para estagiários, quanto para docentes, caracterizandose como um recurso que facilita a troca de conhecimento e experiências, rompendo com o pensamento ainda hegemônico que o professor é a fonte de conhecimento e o estudante o elemento nulo, receptáculo de conhecimentos prontos. No entanto, foi admitido por estudantes e professores que a atitude de alguns docentes destoa da proposta do uso do portfólio enquanto instrumento facilitador da aquisição do conhecimento autônomo e reflexivo, o que não seria uma falha do instrumento, este é considerado eficiente, porém necessita ser acompanhado por ações docentes planejadas.

Alvarenga e Araujo $^{10}$ recomendam a utilização de alguns indicadores para monitoramento da construção do portfólio, por exemplo, organização, documentação e demonstração do conhecimento do aluno sobre o conteúdo desenvolvido; presença de reflexões sobre os temas; evidências que demonstrem como o progresso aconteceu; demonstração do conhecimento obtido e a aplicação do mesmo; reflexões do aluno com os indícios ou indicadores do progresso em aprendizagens factuais, conceituais, atitudinais e procedimentais.

Apesar de nem sempre ser percebido pelo estudante a coerência entre, o que foi construído na elaboração do portfólio, a assistência prestada aos usuários do serviço da clínica escola, e o que foi calculado pelo docente na avaliação, transmitindo para alguns estudantes uma sensação de injustiça e subjetiva ao final do componente curricular, a sensação dos estudantes, apesar de todas as críticas ao instrumento, foi de dever cumprido, desenvolvimento de habilidades e conhecimento, tendo o Portfólio como essencial para um aprendizado completo. Até mesmo quando questionados sobre qual outro instrumento poderia ser utilizado em substituição do portfólio, os estudantes pontuaram que o Portfólio é uma boa forma de avaliação, mas deve ser reestruturado, incorporando uma discussão mais completa sobre o que vai ser feito e possuir a auto-avaliação do aluno como complemento, não tendo outro instrumento como substituto, uma vez que no portfólio o conhecimento é construído e não apenas repassado.

\section{CONCLUSÕES}

A construção do portfólio por estagiários em Clínica Integrada Odontológica se constitui um potente indutor e potencializador do trabalho em equipe, se estabelecendo como estratégia educacional que permite (re)significar e aprofundar 
o conhecimento, ao tempo que propicia a consolidação do aprendizado.

A construção do portfólio clínico exige do estudante um nível de reflexão crítica que favorece o crescimento do estudante, enquanto cidadão e futuro profissional; estimulando a participação ativa nos acontecimentos do mundo real, principalmente aqueles ligados à saúde.

O portfólio acadêmico pode ser admitido como estratégia de ensino, aprendizagem e avaliação formativa, crítica, reflexiva, criativa, dialética que estimula e valoriza a participação do aluno. Ademais, a utilização do portfólio no estágio em odontologia é uma maneira de ampliar, (re) pensar e inovar o ensino de graduação na perspectiva de um instrumento/estratégia de estimulação do pensamento acadêmico.

\section{ABSTRACT \\ Portfolio as teaching, learning and evaluation strategy: perception of students and professors}

This study aimed to analyze the perception of students and professors of dentistry, regarding the creation and presentation of the reflective portfolio such as teaching, learning, and evaluating strategy, in the Integrated Clinic of the Dentistry Course at the Universidade Estadual de Feira de Santana (UEFS). It is a cross-sectional descriptive qualitative study, and the data collection was during the second semester of 2014. The subject of this study was the professors and the students enrolled in the semester. The data consisted of a semi-structured interview with nine questions for students and seven for professors. The data were analyzed by The Content Analysis method. Three hypotheses were tested to present the results; 1 . The use of the portfolio is a strategy that helps the understanding by students and professors about what was taught and, consequently, higher levels of significant learning; 2. The portfolio is an instrument that facilitates the process of reelaboration of knowledge by students and professors. Also, it offers an opportunity for reflection on the progress of students. Besides, it contributes to the self-assessment of both; 3 . The application of the portfolio helps the participative management in the formative assessment strategy. While the professor, who is a facilitator in the development of reflective knowledge, allows the student to develop autonomy, independence, creativity, and self-criticism skills. Thus, the creation of the portfolio by trainees of Integrated Dental Clinic is an inducer and enhancer of teamwork, being an educational strategy that enables a new meaning and deepens knowledge, at the same time, it gives the reinforcement of learning. The creation of the clinical portfolio requires a level of critical reflection that helps the development of the student, as a citizen and professional; encouraging active participation in real-world events, especially those related to health care. The academic portfolio can be established as a teaching, learning, and formative, critical, reflective, creative, and dialectical strategy that encourages and values student participation. The academic portfolio can be used as a teaching, learning, and formative, critical, reflective, creative, and dialectical strategy that encourages and values student participation. Also, in the Dentistry internship, it is a way to expand, rethink and innovate undergraduate education from the perspective of an instrument/strategy for stimulating academic thinking.

Descriptors: Portfolio. Teaching. Educational Evaluation.

\section{REFERÊNCIAS}

1. Cotta RMM, Silva LS, Lopes LL, Gomes KO, Cotta FM, Lugarinho R, Mitre SM. Construção de portfólios coletivos em currículos tradicionais: uma proposta inovadora de ensino-aprendizagem. CSC. 2012; 17(3): 787-96.

2. Torres SCG. Portfólio como instrumento de aprendizagem e suas implicações para a prática pedagógica reflexiva. RDE. 2008; 8(24):549-61.

3. Villas Boas BMF. O portfólio no curso de pedagogia: ampliando o diálogo entre professor e aluno. RES 2005; 26(90): 291306. 
4. Minayo MCS. O desafio do conhecimento: pesquisa qualitativa em saúde. São Paulo: Ed. Hucitec, 2006.

5. Souza MNC, Cruz CA, Santos AMSA, Cândido AL. Conhecimento de discentes sobre metodologia ativa na construção do processo de ensino aprendizagem inovador. RIEC. 2018; 1 (1): 61-74.

6. Silva EF, Amorim EDBC, Melo MJMD. Prática pedagógica: orientações para a construção do portfólio. Natal: Instituto Kennedy, 2004.

7. Forte FDS, Vieira LB, Pessoa TRRF, Freitas CHSM, Ferreira MLSM. Portfólio: desafio de portar mais do que folhas: a visão do docente de odontologia. RBEM. 2012; 36 (1; supl 2): 25-32.
8. Macedo KDS, Costa BS, Silva EB, Souza NS, Beck CLC, Silva KKD. Metodologias ativas de aprendizagem: caminhos possíveis para inovação no ensino em saúde. EAN 2018;22(3): e20170435.

9. Villas Boas, B.M.F. Portfólio, avaliação e trabalho pedagógico. $7^{a}$ edição. Campinas (SP). Papirus, 2004.

10. Alvarenga GM, Araujo ZR. Portfólio: conceitos básicos e indicações para sua utilização. Est Aval Educ. 2006; 17(33):13748.

\section{Correspondência para:}

Lydia de Brito Santos

e-mail: 1ydiabs@gmail.com

Rua Professor Sabino Silva, 322/501

44.001-264 Feira de Santana/BA 